\title{
TRANSLOCATION OF TRANSITION METALS DURING THE DEGRADATION OF PINUS RADIATA BY GLOEOPHYLLUM TRABEUM ON THE FOREST SOIL
}

\author{
CLAUDIO POZO ${ }^{1}$, VICTORIA MELÍN², JUAN PEDRO ELISSETCHE², DAVID CONTRERAS ${ }^{24}$, \\ JUANITA FREER ${ }^{24}$, JAIME RODRÍGUEZ ${ }^{23}$
}

\author{
${ }^{l}$ Centro de Investigación de Polímeros Avanzados (CIPA) CONICYT- REGIONAL R08C1002. Avda. Collao No 1202 Edificio Lab. CIPA, Concepción, Chile \\ ${ }^{2}$ Centro de Biotecnología, Universidad de Concepción. Barrio Universitario s/n, Casilla 160-C, Concepción, Chile \\ ${ }^{3}$ Facultad de Ciencias Forestales, Universidad de Concepción. Victoria 631, Casilla 160-C, Concepción, Chile \\ ${ }^{4}$ Facultad de Ciencias Químicas, Universidad de Concepción. Edmundo Larenas 129, Casilla 160-C, Concepción, Chile
}

\begin{abstract}
Brown rot fungi (BRF) are highly destructive wood degraders characterized by extensive degradation and mineralization of cellulose and hemicellulose, in most of the cases without causing a substantial removal of lignin. BRF have not a complete cellulase complex neither ligninolytic enzymes, therefore, has been hypothesized that to degrade wood components, a non-enzymatic mechanism based on $\bullet \mathrm{OH}$ radicals production through Fenton reaction is also involved. The availability of iron limits the Fenton reaction in wood biodegradation by BRF, because this metal (and other transition metals) is found in small amounts in wood. For this reason, it has been postulated that the fungus transport metals from the soil. To study the effect of soil and transition metal translocation (Fe, $\mathrm{Cu}$, and $\mathrm{Mn}$ ) on wood biodegradation by the BRF Gloeophyllum trabeum, Pinus radiata wood chips (20 years old) were incubated with forest soil in stationary tray bioreactor for a period until 16 weeks. Translocation of transition metals, mass and wood components (extractives, carbohydrates, and lignin) loss, the decrease of holocellulose viscosity and oxalic acid production were determined at different intervals of time.
\end{abstract}

Wood on soil showed a high translocation of transition metals mainly Fe. Translocation of soil metals into the wood was relevant for improving fungal growth and wood decay, which is correlated significantly with higher loss mass and wood components compared with degradation without soil.

Keywords: brown rot, wood biodegradation, metal translocation, Gloeophyllum trabeum, forest soil, transition metals

\section{INTRODUCTION}

Brown rot fungi (BRF) are a group of wood-inhabiting fungi characterized by degrading mainly wood carbohydrate and in most of the case modifying lignin, with slight degradation. Instead to initiate the wood degradation process employing hydrolytic enzymes, BRF have developed a mechanism based on low molar mass iron reducing compounds, which promote Fenton reaction ${ }^{1-6}$.

Fenton reaction $(\mathrm{Fe}(\mathrm{II})+\mathrm{H} 2 \mathrm{O} 2 \rightarrow \mathrm{Fe}(\mathrm{III})+-\mathrm{OH}+\cdot \mathrm{OH})$ is involved in the wood decay by BRF generating hydroxyl radicals from hydrogen peroxide, which oxidize organic molecules 5 . Low molar mass dihydroxybenzenes (DHBs) and demethylated lignin produced during wood biodegradation, promote Fenton reaction by iron chelation and reduction ${ }^{7}$. In the first biodegradation stages, a fast holocellulose depolymerization is made ${ }^{8}$, causing a rapid loss of wood strength ${ }^{9}$. BRF degrade preferably hemicellulose and cellulose, and modifying lignin through demethylation ${ }^{10,11}$, and oxidation of the side chain of lignin in a lesser degree. Has been hypothesized that lignin could be first depolymerized, and later reconnected via radical coupling of the phenolic units that become enriched during the attack on the aromatic rings by $\cdot \mathrm{OH}^{12,13}$.

Wood-degrading basidiomycetes are an important component in the nutrient cycling of the element. They can acquire mineral nutrients from the soil and translocate it to sites of demand through mycelial networks, which can connect dead wood, litter decomposition and soil ${ }^{14,15}$. Most of the wood decaying fungi form mycelial networks at the soil-litter interface during the search for fresh organic resources or while scavenging for mineral nutrients ${ }^{16}$. Wood decay fungi can translocate significant quantities of $\mathrm{C}$, nutrients (especially $\mathrm{N}, \mathrm{P}$, and $\mathrm{S}$ ), and base cations through their mycelial cord and rhizomorph systems ${ }^{17,18}$, which represents a significant advantage for growth in soil ${ }^{19}$. Translocation is often viewed as an unidirectional process, with movement from a nutrient source (e.g. soil) to a sink (e.g. wood). However, bidirectional translocation of nutrients by wood decay fungi has also been observed ${ }^{17,18}$.

Iron, manganese, and copper are involved in many physiological processes and BRF also in the generation of hydroxyl radicals or other oxidizing agents, by Fenton reaction ${ }^{20}$. The total iron concentration in wood is usually lower than $2 \mu \mathrm{mol}^{*} \mathrm{~g}^{-1}$ in non-degraded wood ${ }^{21}$, it can be hardly found as a free cation due to their limited solubility in a neutral $\mathrm{pH}$ environment, but is attached to the wood cellulose ${ }^{22,23}$ and forming oxyhydroxides ${ }^{21}$. However, they can be translocated through the mycelial networks in the form of chelates which gives mobility and can cross the cytoplasmic membrane.

Oxalic acid (OA) is an important physiological metabolite, produced by $\mathrm{BRF}$ in a high amount ${ }^{24}$. The concentration of OA around the fungal hyphae appears to be tightly regulated, lowering the $\mathrm{pH}$ away from fungal hyphae and it is essential in the decay process caused by BRF ${ }^{25}$. Iron can be sequestered from $\mathrm{Fe}$-oxyhydroxides to form $\mathrm{Fe}$-oxalate complexes that can then diffuse into the wood cell wall ${ }^{26}$. Secreted oxalic and another organic acid may also promote brown rot by weathering soil minerals and solubilization of metal cations ${ }^{27,28}$.

In previous works ${ }^{29-31}$, metal translocation from soil or another inert support to wood by white rot fungi (WRF) and BRF was studied. In addition, several works have related the oxalic acid production with the metals mobility $27,28,31$, but its specific role in the active metals translocation from soil to wood has not studied and has not been established the role of soil in the rate of holocellulose depolymerization.

The aim of this study was to evaluate the translocation of transition metals $(\mathrm{Fe}, \mathrm{Mn}$, and $\mathrm{Cu})$ during the degradation of Pinus radiata by Gloeophyllum trabeum on the forest soil.

\section{EXPERIMENTAL}

\subsection{Chemical}

In all experiments and analyzes nanopure water (NPW) was used. For culture medium: $0.5 \%$ Soy protein acid hydrolysate (Sigma); $1.5 \%$ Agar-agar for microbiology (Merck); $2 \%$ Malt extract for microbiology (Merck). For chemical analysis (unless otherwise stated, all reagents were p.a. grade): Oxalic acid dihydrate $99 \%$ (Sigma); Nitric acid $65 \%$ (Merck); Sodium chloride 80 $\%$ (Fluka); Copper(II) ethylenediamine solution (Merck), Sulphuric acid $98 \%$ (Merck); Acetone $99 \%$ (Merck).

2.2 Fungus, inoculum preparation and wood biodegradation

Three treatments were performed, Control 01 (C-01) for wood chip incubated without soil, Control 02 (C-02) for uninoculated chips wood on the soil, and the third treatment (WS) for inoculated chips wood incubated on the soil. C-01 and WS treatments were incubated for $0,1,2,3,4,8,12$ and 16 weeks. C-02 was incubated for $0,4,8,12$ and 16 weeks. All the experiments were carried out in triplicate.

Radiata pine wood chips with $2.5 \mathrm{~cm}$ in the longitudinal plane, $1.8 \mathrm{~cm}$ 
width in the tangential plane and $0.4 \mathrm{~cm}$ in the transversal plane were prepared from a 20-year old tree harvested in the Bio-Bio Region of Chile. Transverse sections were chipped according to Elissetche et al. (2006) ${ }^{30}$. These wood chips were then immersed in water for $24 \mathrm{~h}$; the residual water was drained off before autoclaving for inoculation.

A stationary tray bioreactor according to the method proposed by Akhtar et al. (1992) ${ }^{32}$ was used. The bioreactor consisted of a plastic tray with dimensions of $30 \mathrm{~cm}$ (length) $\times 20 \mathrm{~cm}$ (width) $\times 7 \mathrm{~cm}$ (height). For C-02 and WS treatments, chips were placed on $250 \mathrm{~cm}^{3}$ of sieved mineral soil obtained in a forest to Concepcion, Chile $\left(36^{\circ} 50^{\prime} 29^{\prime}\right.$ ' $\left.\mathrm{S}, 73^{\circ} 1^{\prime} 33^{\prime \prime} \mathrm{O}\right)$. The forest soil corresponding from native Chilean forest growing in metamorphic soil was sieved to eliminate the organic matter and separate the mineral layer. For all treatments, $300 \mathrm{~g}$ (on dry basis) of autoclaved chips were put in tray bioreactors.

To avoid diffusion of metals in the autoclave, wood and soil were independently sterilized at $121{ }^{\circ} \mathrm{C}$ for $20 \mathrm{~min}$ and cooled to room temperature before inoculation. The final moisture of wood was about $60 \%$ and $37 \%$ for soil.

Gloeophyllum trabeum (ATCC 11539) cultures were maintained in water at $4{ }^{\circ} \mathrm{C}$ and before experiments it was grown in agar glass plates $(9 \mathrm{~cm}$ diameter) by 7 days at $25^{\circ} \mathrm{C}$. Erlenmeyer flasks $(2000 \mathrm{~mL})$ containing $200 \mathrm{~mL}$ of medium, composed of $2 \%$ malt extract and $0.5 \%$ soybean peptone, were inoculated with 20 discs ( $8 \mathrm{~mm}$ diameter) of a G. trabeum precultured on agar medium. These liquid cultures were maintained unshaken for 15 days at $25^{\circ} \mathrm{C}$. The mycelial pellets were then removed by filtration and washed with $500 \mathrm{~mL}$ sterile water. Washed mycelium obtained from several cultures was blended using home blender previously sterilized with $100 \mathrm{~mL}$ sterilized water in 3 cycles of $15 \mathrm{sec}$ and then used to inoculate the wood chips.

Inoculation of wood chips for WS treatments was performed before putting the wood on the soil. A mycelium mass/wood ratio of $1 \mathrm{~g} / \mathrm{kg}$ (on dry basis) was used. The C-02 was treated identically except that it was not inoculated. Each stationary tray bioreactor was placed inside a sterile polypropylene containment bag. Cultures were incubated at $25{ }^{\circ} \mathrm{C}$ statically during the biodegradation period.

After biodegradation, the wood chips were separated from the soil, dried at $45{ }^{\circ} \mathrm{C}$ for $48 \mathrm{~h}$ and stored in dry conditions for further characterization. The mycelium on the wood surface was not removed. Undecayed wood chips (controls) were processed in a similar manner to the inoculated chips. Weight loss was calculated based on the initial and final dry weights. All values were corrected for weight loss except where otherwise noted.

\subsection{Chemical analysis of the wood chips}

For chemical analysis, air-dried wood chips were milled in a knife mill (Manesco\&Ranieri) through an 18 mesh. To obtain a representative sample, each one was mixed and partitioned using a quartering method ${ }^{33}$. Approximately $1 \mathrm{~g}$ of sample was extracted with $99 \%$ acetone for $16 \mathrm{~h}$ in a Soxhlet apparatus following standard method (TAPPI Test Method T 280 pm-99).

Total lignin content was determined by the sum of Klason lignin and soluble lignin in aqueous fraction. Klason lignin was determined in extractivefree wood samples according to TAPPI Standard T 222 om-98, 1998 TAPPI Standard T 222 om-98, 1998. Acid insoluble lignin in wood and pulp. TAPPI T222 om-98 (1998). Soluble lignin in the aqueous fraction was determined by measuring the absorbance at $205 \mathrm{~nm}$, using the value of $105 \mathrm{Lg}^{-1} \mathrm{~cm}^{-1}$ as the absorptivity of soluble lignin ${ }^{34}$. The concentrations of monomeric sugars in the aqueous fraction were determined by HPLC ${ }^{35}$ using a BIORAD HPX-87H column at $45^{\circ} \mathrm{C}$, eluted at $0.6 \mathrm{mLmin}^{-1}$ with $5 \mathrm{mM}$ sulphuric acid. The chemical composition values were the mean of duplicate hydrolysis experiments, deviation from the mean being $<3 \%$.

Chlorite holocellulose was prepared using the procedure following standard method (TAPPI Standard T-9m-54). For this procedure, the volume and weight were scaled in proportion to the mass of air-dried wood used in each preparation. The viscosity of different samples of hollocellulose was measured by the standard method (TAPPI Test Method T 230 om-04) using cupriethylendiamine (CED) as a solvent and an Ostwald viscometer, to give an indication of the average degree of polymerization of the hollocellulose. Intrinsic viscosities were obtained using the Solomon-Gotessman equation ${ }^{36}$.
Oxalic acid was determined by HPLC as described by Hunt et al. (2004) ${ }^{37}$ using detection at $210 \mathrm{~nm}$. Extracts $(80 \mathrm{~mL})$ were injected into a strong cationexchange resin column, $\mathrm{H}+($ Bio-Rad Aminex HPX-87 particle size $9 \mu \mathrm{m}, 300$ $\times 7.8 \mathrm{~mm} \mathrm{I}$. D.) with $0.005 \mathrm{~N} \mathrm{H}_{2} \mathrm{SO}_{4}$ eluent at $0.6 \mathrm{~mL} \mathrm{~min}$ and $67^{\circ} \mathrm{C}$. An oxalic acid standard was prepared and run before the extracts.

The metal content of the soil, wood, and the wood-fungus complex was measured following Tappi Standard T266 om-94. Milled samples $(500 \mathrm{mg})$ were hydrolysed with $6 \mathrm{~mL}$ concentrated sulphuric acid in a Digesdahl Hach digester heated for $5 \mathrm{~min}$ at $440^{\circ} \mathrm{C}$. Then $3 \mathrm{~mL} 30 \%(\mathrm{w} / \mathrm{w})$ hydrogen peroxide was added, and the mixture was heated at $440{ }^{\circ} \mathrm{C}$ for an additional $3 \mathrm{~min}$. After cooling, the solution was made up to $50 \mathrm{~mL}$ with deionized water. This solution was analyzed by an ICP-GBC Integra XM equipment to determine manganese, iron and copper contents ${ }^{30}$. Metal concentrations in biotreated wood samples were corrected for weight loss values according to the method described by Ostrofsky et al. (1997) ${ }^{29}$.

\subsection{Statistical analysis}

An ANOVA test was performed to determine whether the experiments differed significantly. A multiple comparison procedure (multiple range test) was then used to find which means of methods were significantly different at the $95.0 \%$ confidence level. The method used to discriminate between the means was the Fisher's least significant difference (LSD) procedure. Comparison between two samples was assessed using a Student's t-test for independent samples $(P<0.05)$. All statistics were obtained using Statgraphics Plus 3.1 software (Manugistics Inc., Rockville, USA).

\section{RESULTS AND DISCUSSION}

3.1 Wood biodegradation process

Losses of wood weight and components caused by G. trabeum over a biodegradation periods from 0 to 16 weeks are shown in Fig. 1. Decayed wood chips for C- 01 and WS treatments both exhibited progressive weight loss during the experiment reaching weight loss values by $21.5 \%$ and $38.5 \%$, respectively for 16 weeks. In both C-01 and WS treatments, the fungus with the formation of abundant mycelial mass rapidly colonized wood chips after the first 4 weeks of incubation and at the end (16 weeks) the mycelium covered the wood chips in such a way that the wood was no longer visible. In general, wood chips degraded for WS exhibited better fungal growth, and wood decay was more pronounced than in wood chips degraded for C- 01 . The weight loss between both C-01 and WS treatments showed a significant difference in the 2 week after initial $(P=0.034)$. Decayed wood for WS lost approximately 8.6 $\%$ of its weight the first 4 weeks while C-01 lost only $3.6 \%$ during this time interval.

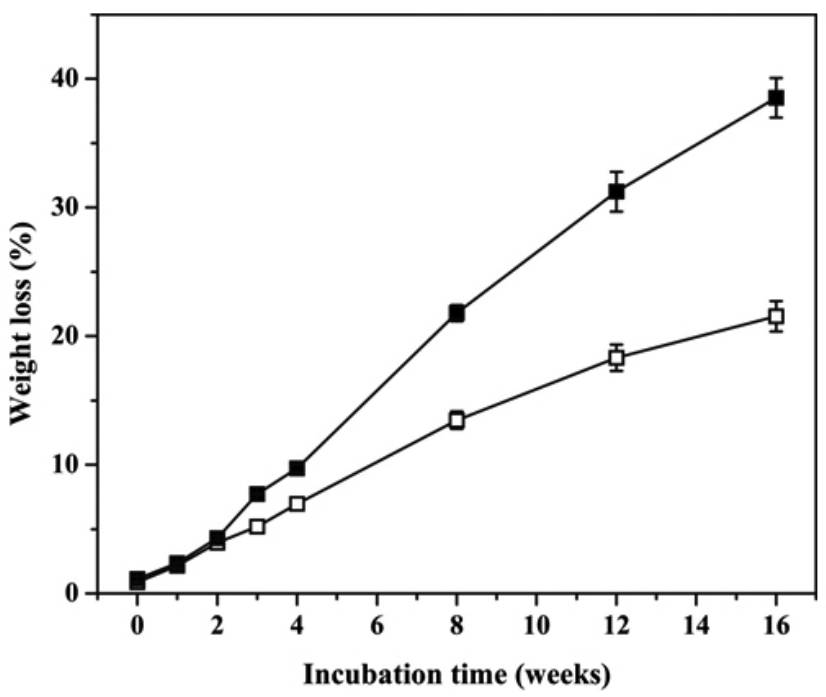

Figure 1. Temporal variation of weight loss in radiate pine wood chips incubated with G. trabeum. C-01 (light colors) and WS (dark colors) treatments. Error bars represent SD from triplicate experiment and where not shown are smaller than the symbol. 
In both cases, the weight loss is related primarily to carbohydrate loss showing a high correlation for $\mathrm{C}-01(r=0.959)$ and WS $(r=0.983)$ treatments.

Carbohydrate loss between for C-01 and WS treatments showed a significant difference after 4 weeks of biodegradation $(P=0.003)$ and reached values by $26.7 \%$ and $38.1 \%$ respectively after 16 weeks (Fig. 2); lignin has a lower mass loss. This is consistent with the known wood decay pathways of $\mathrm{BRF}^{9}$. The lignin loss for C-01 and WS both exhibited values by $1.7 \%$ and 5.1 $\%$, respectively for 16 weeks. The comparison to the period of C-01 and WS treatments shows no significant difference. As previously reported BRF do not degrade lignin extensively ${ }^{38-41}$ but chemically modify it ${ }^{11,42}$. With increasing time in the degradation, the chips wood progressively turned dark brown taking on a friable texture and shrinking in volume with time. This change is characteristic of BRF decay and was observed mainly for WS after 16 weeks of biodegradation. Nitrogen and organic carbon available in the soil could contribute to intense fungal growth. Nevertheless, the metallic ions present in the soil could also enhance the fungal capacity to degrade wood. Among several metals, manganese, iron, and copper are known to be necessary for fungal metabolism (Elissetche et al., 2006) ${ }^{30}$.

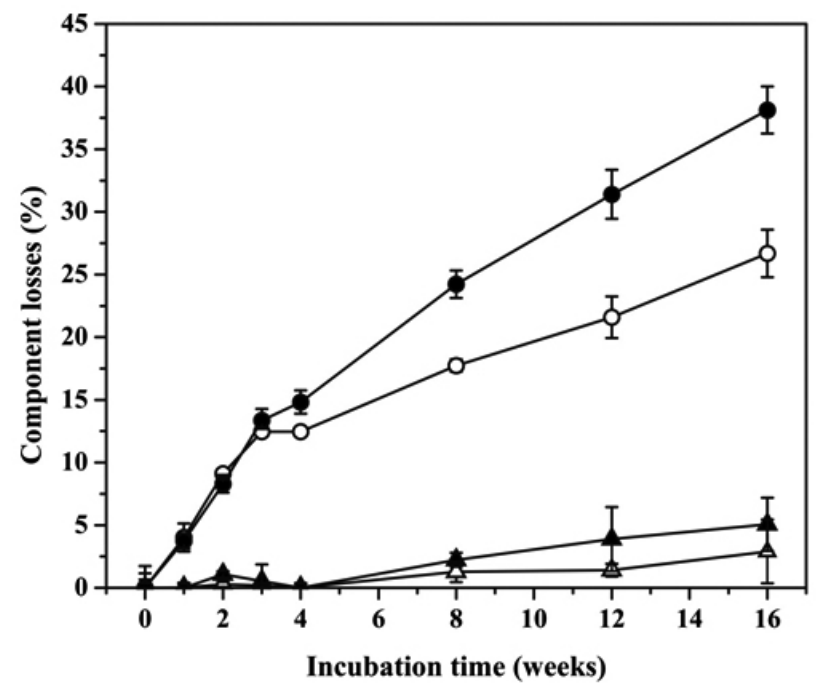

Figure 2. Components losses of radiate pine wood chips incubated with G. trabeum. C-01 (light colors) and WS (dark colors) treatments. Symbols: carbohydrates (circles), lignin (triangles).

In both treatments, the effect of biodegradation is similar in hemicelluloses. Mannans for C- 01 and WS both reached values by $7.6 \%$ and $6.7 \%$ respectively and arabinans, $0.50 \%$ and $0.45 \%$ respectively for 16 weeks. Fig. 3 shows carbohydrates remaining on decayed wood. However, weight loss is related primarily to the loss of glucans showing a high correlation for C-01 $(r=-0.942)$ and WS $(r=-0.992)$ treatments. The comparison by the periods of remaining glucans between both treatments showed a significant difference from the 4 week $(P=0.003)$ reaching values by $40.7 \%$ and $33.4 \%$ respectively for 16 weeks. This effect is because BRF always removes hemicelluloses before amorphous and crystalline cellulose ${ }^{9}$. Arabinan degradation is more prominent than mannan in the early phase of decay. Arabinans in softwood are mainly associated with pectic substances located in middle lamellae and primary cell walls where incipient degradation is found (Fackler, 2010) ${ }^{43}$

\subsection{Holocellulose depolymerisation}

The comparison by the periods of holocellulose loss between C-01 and WS treatments showed a significant difference after 4 weeks of biodegradation $(P=0.003)$ and reached values by $28.1 \%$ and $40.8 \%$ respectively for 16 weeks (Fig. 2 and 4a). Holocellulose loss is highly correlated with mass loss mainly for WS $(r=-0.943)$. Holocellulose depolymerization degree is consistent with previous studies that have shown that BRF rapidly depolymerizes holocellulose in the early stages of biodegradation ${ }^{8}$, the Fig. $4 \mathrm{~b}$ shows the viscosity of holocellulose remaining on decayed wood for $\mathrm{C}-01$ and WS treatments, where it is observed similar behavior in the degree of depolymerization independent of treatment. The viscosity decreased in early stages of biodegradation, especially before 4 weeks, and then remain constant over time, this may be because the
BRF after the initial depolymerization of holocellulose uses immediately low molecular weight sugars formed in their metabolism, so the polymerization degree of holocellulose remains a constant value. The comparison between $\mathrm{C}-01$ and WS by the periods showed no significant difference $(p<0.05)$.

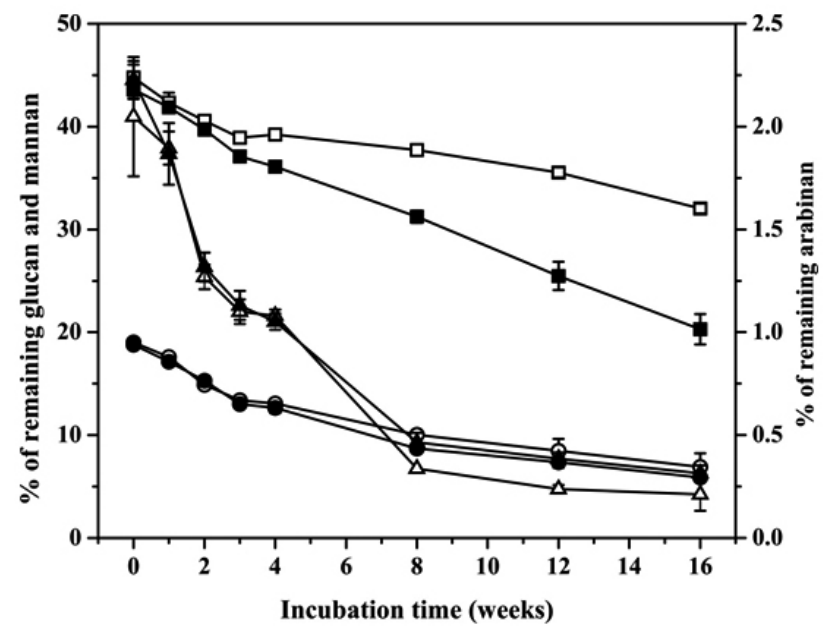

Figure 3. Remaining glucan, mannan, and arabinan of radiata pine wood chips incubated with G. trabeum. C-01 (light colors) and WS (dark colors) treatments. Symbols: glucan (squares), mannan (circles), arabinan (triangles).
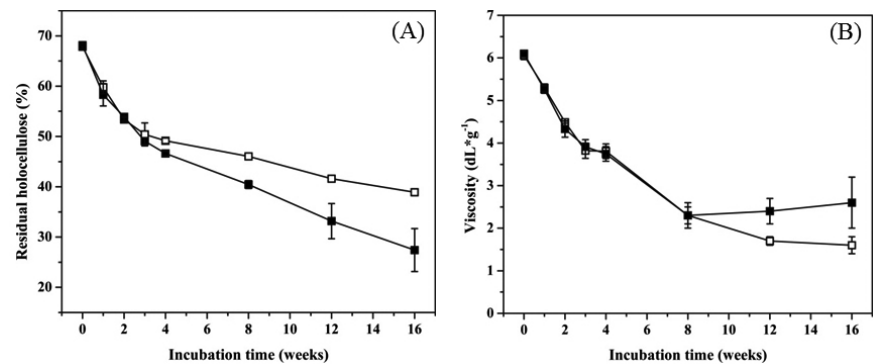

Figure 4. Residual holocellulose (A) and viscosity (B) of radiata pine wood chips incubated with G. trabeum. C-01 (light colors) and WS (dark colors) treatments. Values of viscosity no corrected by weight loss

\subsection{Metal translocation}

During the biodegradation, translocation of the transition metals Fe, Mn and $\mathrm{Cu}$ from soil to wood was observed. The translocation of metals is related to the high availability of these metal ions in the soil (Table 1). It can be seen that for C-01 treatments showed no significant difference between means for $\mathrm{Fe}(P=0.057), \mathrm{Mn}(P=0.129)$ and $\mathrm{Cu}(P=0.879)$ due to the absence of soil. The comparison by the periods of $\mathrm{Fe}$ and $\mathrm{Cu}$ between $\mathrm{C}-01$ and WS treatments showed a significant difference from the 4 week $(P=0.000)$ and Mn from the 8 week $(P=0.000)$.

C-01 and C-02 showed no significant difference $(P=0.000)$ for the three metals studied, suggesting that under the experimental conditions developed in this work $100 \%$ of the metals translocation from moist soil to wood in ground contact was carried out in the fungal symplast and not due to a passive 'wicking' action ${ }^{17}$. In contrast, the comparison between C-01 and WS shows a significant difference from the first week for $\mathrm{Fe}(P=0.016)$ and $\mathrm{Mn}(P=0.013)$, and from the third week for $\mathrm{Cu}(P=0.033)$. The higher translocation was to $\mathrm{Fe}$ where the concentration of this metal in the biodegraded wood reached 14 $\mu \mathrm{mol}^{*} \mathrm{~g}^{-1}$ dry wood more than 20 times the value of non-degraded wood.

The high mobility of the metals can be explained because the metals in organic soil are complexed with humic substances forming complexes of different stability ${ }^{44}, 45$. Humic substances are ubiquitous in soils and are often intimately associated with clay minerals from which can uptake minerals to solution phase ${ }^{44}$. It is likely that the humic portion of soil containing the breakdown residues of wood, function as metal-reducing and promoting oxidative reactions in biodegradation processes in wood ${ }^{7}$. On the other hand, 
chelating agents are secreted by fungi, promoting Fe(III) solubilization and further transfer into the wood during biodegradation ${ }^{1}$. Some iron-chelating compounds show $\mathrm{Fe}(\mathrm{III})$ reducing activity and have a key role in wood biodegradation by brown-rot fungi ${ }^{6,9}$.

Table 1. Metal content of radiate pine wood decayed by G. trabeum.

Metal concentration in soil $(\mu \mathrm{mol} / \mathrm{g} \text { dry soil })^{1}$

$\mathrm{Fe}$

$877.40 \pm 10.74$

$\mathrm{Mn}$

$31.85 \pm 0.18$
$\mathrm{Cu}$

$0.398 \pm 0.005$

Metal concentration in wood $(\mu \mathrm{mol} / \mathrm{g} \text { dry wood })^{2,3}$

\begin{tabular}{|c|c|c|c|c|c|c|c|c|c|}
\hline $\begin{array}{l}\text { Incubation } \\
\text { time (weeks) }\end{array}$ & C- 01 & C- 02 & WS & C- 01 & C- 02 & WS & C- 01 & C- 02 & ws \\
\hline 0 & $0.38 \pm 0.02^{2}$ & $0.48 \pm 0.02 a$ & $0.69 \pm 0.06^{2}$ & $0.48 \pm 0.02^{2}$ & $0.48 \pm 0.02^{a}$ & $0.53 \pm 0.01^{2}$ & $0.027 \pm 0.002^{2}$ & $0.027 \pm 0.002^{2, b}$ & $0.019 \pm 0.006^{2}$ \\
\hline 1 & $0.35 \pm 0.02^{a}$ & & $1.22 \pm 0.21^{\mathrm{a}}$ & $0.51 \pm 0.02^{a}$ & & $0.70 \pm 0.04^{a}$ & $0.022 \pm 0.009^{\mathrm{a}}$ & & $0.031 \pm 0.004^{2,8}$ \\
\hline 2 & $0.40 \pm 0.04^{a}$ & & $3.75 \pm 0.63^{a, b}$ & $0.51 \pm 0.04^{\mathrm{a}}$ & & $0.87 \pm 0.09^{a}$ & $0.032 \pm 0.008^{2}$ & & $0.053 \pm 0.006^{b}$ \\
\hline 3 & $0.34 \pm 0.05^{\mathrm{a}}$ & & $5.04 \pm 0.33^{b}$ & $0.51 \pm 0.05^{\mathrm{a}}$ & & $1.22 \pm 0.01^{a}$ & $0.023 \pm 0.000^{\mathrm{a}}$ & & $0.048 \pm 0.009^{b, c}$ \\
\hline 4 & $0.38 \pm 0.04^{2}$ & $0.49 \pm 0.02^{a, b}$ & $6.77 \pm 1.95^{\circ}$ & $0.52 \pm 0.04^{a}$ & $0.49 \pm 0.02^{a}$ & $1.47 \pm 0.12^{\mathrm{a}}$ & $0.032 \pm 0.006^{\mathrm{a}}$ & $0.026 \pm 0.003^{2, b}$ & $0.052 \pm 0.006^{b}$ \\
\hline 8 & $0.48 \pm 0.06^{\mathrm{a}}$ & $0.52 \pm 0.07^{\mathrm{a}, \mathrm{b}}$ & $11.97 \pm 1.70^{\circ}$ & $0.51 \pm 0.06^{\mathrm{a}}$ & $0.52 \pm 0.07^{\mathrm{a}}$ & $2.83 \pm 0.79^{b}$ & $0.028 \pm 0.021^{a}$ & $0.028 \pm 0.003^{\mathrm{a}, \mathrm{b}}$ & $0.065 \pm 0.014^{\circ}$ \\
\hline 12 & $0.45 \pm 0.07^{\mathrm{a}}$ & $0.52 \pm 0.01^{b}$ & $12.50 \pm 2.43^{\mathrm{c}}$ & $0.69 \pm 0.07^{b}$ & $0.52 \pm 0.01^{a}$ & $3.55 \pm 0.77^{b}$ & $0.027 \pm 0.017^{2}$ & $0.031 \pm 0.003^{b}$ & $0.110 \pm 0.015^{d}$ \\
\hline 16 & $0.47 \pm 0.06^{\mathrm{a}}$ & $0.65 \pm 0.02^{c}$ & $14.12 \pm 0.14^{\mathrm{c}}$ & $0.70 \pm 0.06^{\mathrm{b}}$ & $0.65 \pm 0.02^{b}$ & $5.15 \pm 0.70^{\circ}$ & $0.024 \pm 0.009^{\mathrm{a}}$ & $0.022 \pm 0.006^{\mathrm{a}}$ & $0.131 \pm 0.008^{d}$ \\
\hline
\end{tabular}

${ }^{1,2}$ Data are shown as a mean \pm confidence interval.

${ }^{3}$ Values of metal concentration in wood was corrected by mass loss

a-d Means within a row whit different superscripts differ significantly $(P<0.05)$.

3.4 Oxalic acid production

Similar behavior between $\mathrm{C}-01$ and WS treatment for oxalic acid production in the first 8 weeks (Fig. 5) can be explained because the BRF produce this metabolite in great quantities in the early stages of wood decay ${ }^{24}$ and is used by the fungus in the biodegradation process ${ }^{25,26}$. From the 8 week, it was observed an increase in the production of oxalic acid for WS treatment. Oxalic acid production between $\mathrm{C}-01$ and WS treatments showed a significant difference after 12 weeks of biodegradation $(P=0.019)$.

The increase in oxalic acid production may be related to its role as metal chelator ${ }^{26}$ and may also promote brown rot by weathering soil minerals and solubilization of metal cations 27,28 . This is reflected in the high correlation for WS treatment between oxalic acid and Fe $(r=0.917), \mathrm{Mn}(r=0.945), \mathrm{Cu}$ $(r=0.976)$ and weight loss $(r=0.943)$.

\section{CONCLUSIONS}

The metals translocation from moist soil to wood was carried out in active form by the fungal symplast; this generated an increase in the concentration of wood metals mainly Fe, resulting an acceleration of the biodegradation process. The active metals translocation was accompanied by an increase in the oxalic acid production, showing this metabolite a high correlation with weight and wood component losses for WS treatments. The acceleration of biodegradation process had no effect on the holocellulose depolymerization.

\section{ACKNOWLEDGEMENTS}

This work was supported by FONDECYT 1100898, FONDECYT 11090312, Conicyt (Claudio Pozo Ph.D. fellowship) and CIPA Conicyt-Regional R08C1002 is gratefully acknowledged.

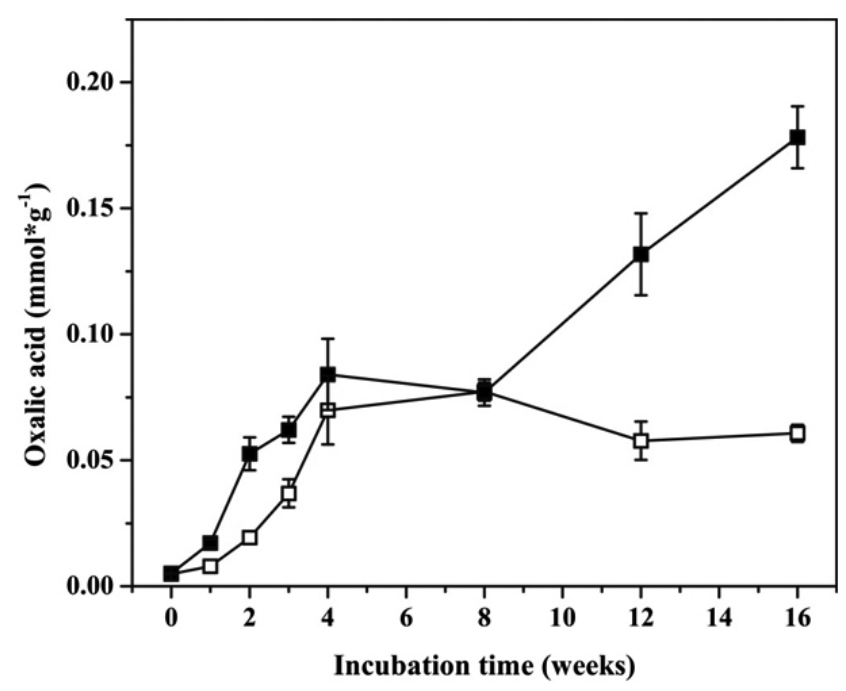

Figure 5. Oxalic acid concentration in aqueous extract of radiata pine wood chips incubated with G. trabeum. C-01 (light colors) and WS (dark colors) treatments. Values no corrected by weight loss.

\section{REFERENCES}

1. S. M. Hyde and P. M. Wood, Microbiology, 1997, 143(1), 259-266.

2. B. Goodell, J. Jellison, J. Liu, G. Daniel, A. Paszczynski, F. Fekete, S. Krishnamurthy, L. Jun, and G. Xu, J. Biotechnol., 1997, 53(2-3), 133-162.

3. Z. Kerem, K. A. Jensen, and K. E. Hammel, FEBS Lett., 1999, 446(1), 4954.

4. K. A. Jensen, Jr., C. J. Houtman, Z. C. Ryan, and K. E. Hammel, Appl. Environ. Microbiol., 2001, 67(6), 2705-2711.

5. K. E. Hammel, A. N. Kapich, J. K. A. Jensen, and Z. C. Ryan, Enzyme Microb. Technol., 2002, 30(4), 445-453. 
6. J. Rodriguez, A. Ferraz, and M. P. Mello: 'Role of metals in wood biodegradation', in 'Wood Deterioration and Preservation. ACS Symposium Series 845', (eds. B. Goodell, et al.), 154-174; 2003, Washington DC American Chemical Society.

7. B. Goodell, G. Daniel, J. Jellison, and Y. Qian, Holzforschung, 2006, 60(6), 630-636

8. M. R. Suzuki, C. G. Hunt, C. J. Houtman, Z. D. Dalebroux, and K. E. Hammel, Environ. Microbiol., 2006, 8(12), 2214-2223.

9. B. Goodell: 'Brown-rot fungal degradation of wood: our evolving view', in 'Wood deterioration and preservation. ACS Symposium series 845', (eds. B. Goodell, et al.), 97-118; 2003, Washington DC

10. M. Lopretti, D. Cabella, J. Morais, and A. Rodrigues, Process Biochem., 1998, 33(6), 657-661

11. T. R. Filley, G. D. Cody, B. Goodell, J. Jellison, C. Noser, and A. Ostrofsky, Org. Geochem., 2002, 33(2), 111-124.

12. D. J. Yelle, J. Ralph, F. Lu, and K. E. Hammel, Environ. Microbiol., 2008, 10(7), 1844-1849.

13. D. J. Yelle, D. Wei, J. Ralph, and K. E. Hammel, Environ. Microbiol., 2011, 13(4), 1091-1100.

14. J. W. G. Cairney, Mycol. Res., 2005, 109(1), 7-20.

15. L. Boddy and T. H. Jones: 'Mycelial responses in heterogeneous environments: parallels with macroorganisms', in 'Fungi in the environment', (eds. G. Dadd, et al.), 112-140; 2007, Cambridge, UK, Cambridge University Press.

16. L. Boddy, Mycol. Res., 1993, 97(6), 641-655.

17. J. H. Connolly and J. Jellison, Int. Biodeterior. Biodegrad., 1997, 39(2-3), 181-188.

18. B. r. Lindahl, R. Finlay, and S. Olsson, New Phytol., 2001, 150(1), 189194.

19. J. M. Wells, L. Boddy, and R. Evans, New Phytol., 1995, 129(3), 467-476.

20. W. P. Henry: 'Non-enzymatic iron, manganese, and copper chemistry of potential importance in wood decay', in 'Wood deterioration and preservation. ACS Symposium series 845', (eds. B. Goodell, et al.), 175195; 2003, Washington DC.

21. J. Jellison, J. Connolly, B. Goodell, B. Doyle, B. Illman, F. Fekete, and A. Ostrofsky, Int. Biodeterior. Biodegrad., 1997, 39(2-3), 165-179.

22. S. M. Kremer and P. M. Wood, Eur. J. Biochem., 1992, 208(3), 807-814.

23. G. Xu and B. Goodell, J. Biotechnol., 2001, 87(1), 43-57.

24. F. Green, M. J. Larsen, J. E. Winandy, and T. L. Highley, Material und Organismen, 1991, 26(3), 191-213.

25. J. A. Micales, Int. Biodeterior. Biodegrad., 1997, 39(2-3), 125-132.

26. V. Arantes, Y. Qian, A. M. F. Milagres, J. Jellison, and B. Goodell, Int Biodeterior. Biodegrad., 2009, 63(4), 478-483.

27. E. P. Burford, M. Fomina, and G. M. Gadd, Mineral. Mag., 2003, 67, $1127-1155$.

28. G. M. Gadd, Mycol. Res., 2007, 111(1), 3-49.

29. A. Ostrofsky, J. Jellison, K. T. Smith, and W. C. Shortle, Can. J. For. Res., 1997, 27(4), 567-571.

30. J.-P. Elissetche, A. Ferraz, J. Freer, and J. Rodríguez, Int. Biodeterior. Biodegrad., 2006, 57(3), 174-178.

31. J. S. Schilling and J. Jellison, Appl. Environ. Microbiol., 2006, 72(8), $5662-5665$

32. M. Akhtar, C. Attridge, C. G. Myers, K. T. Kirk, and R. A. Blanchette, Tappi J., 1992, 75(2), 105-109.

33. D. Harvey: 'Modern analytical chemistry'; 2000, New York, USA,

34. C. W. Dence: 'The Determination of Lignin', in 'Methods in Lignin Chemistry', (eds. S. Lin, et al.), 33-61; 1992, Springer Berlin Heidelberg.

35. A. Ferraz, J. Baeza, J. Rodriguez, and J. Freer, Bioresour. Technol., 2000 , 74(3), 201-212.

36. V. O. F. Solomon and B. S. Gotesman, Die Makromolekulare Chemie, 1967, 104(1), 177-184.

37. C. Hunt, W. Kenealy, E. Horn, and C. Houtman, Holzforschung, 2004, 58, 434-439.

38. J. E. Winandy and J. J. Morrell, Wood Fiber Sci., 1992, 25(3), 278-288

39. A. Machuca and A. Ferraz, Enzyme Microb. Technol., 2001, 29(6-7), 386391.

40. I. Irbe, I. Andersone, B. Andersons, and J. Chirkova, Int. Biodeterior. Biodegrad., 2001, 47(1), 37-45.

41. I. Irbe, B. Andersons, J. Chirkova, U. Kallavus, I. Andersone, and O. Faix, Int. Biodeterior. Biodegrad., 2006, 57(2), 99-106.

42. L. Jin, T. P. Schultz, and D. D. Nicholas, Holzforschung, 1990, 44(2), 133 138.
43. K. Fackler, J. S. Stevanic, T. Ters, B. Hinterstoisser, M. Schwanninger, and L. Salmén, Enzyme Microb. Technol., 2010, 47(6), 257-267.

44. J. F. Stevenson: 'Humus Chemistry: Genesis, Composition, Reactions', 446; 1994, New York, John Wiley \& Sons.

45. G. Davies, A. Fataftah, A. Cherkasskiy, E. A. Ghabbour, A. Radwan, S. A. Jansen, S. Kolla, M. D. Paciolla, L. T. Sein, W. Buermann, M. Balasubramanian, J. Budnick, and B. Xing, J. Chem. Soc., Dalton Trans., 1997, 21, 4047-4060 